\title{
Neuropsychological pattern of striatonigral degeneration: comparison with Parkinson's disease and progressive supranuclear palsy
}

Bernard Pillon, Neziha Gouider-Khouja, Bernard Deweer, Marie Vidailhet, Chara Malapani, Bruno Dubois, Yves Agid

\begin{abstract}
To study the neuropsychological pattern of striatonigral degeneration (SND), 14 consecutive patients with probable SND were submitted to an extensive battery of neuropsychological tests. Compared with controls the performance of patients with SND was impaired on category and phonemic fluency, frontal behaviours, trail making test $A$ and $B$, and free recall of the Grober and Buschke test, but normal on the revised WAIS verbal scale, Raven 47 coloured progressive matrices, Wechsler memory scale, California verbal learning test, Wisconsin card sorting test, and the Stroop interference condition. The performance of patients with SND was also compared with that of 14 patients with Parkinson's disease and 14 patients with progressive supranuclear palsy (PSP) matched for age at onset, duration of disease, severity of intellectual deterioration, and depression. The results showed that the dysexecutive syndrome of SND is similar to that of Parkinson's disease and less severe than in PSP.
\end{abstract}

(F Neurol Neurosurg Psychiatry 1995;58:174-179)

Keywords: striatonigral degeneration; Parkinson's disease; progressive supranuclear palsy

Striatonigral degeneration (SND) is characterised by a parkinsonian syndrome that responds poorly to levodopa treatment, and is associated with signs uncommon in idiopathic Parkinson's disease, such as dysautonomia and pyramidal signs. ${ }^{1}$ Striatonigral degeneration is increasingly diagnosed in parkinsonian patients at postmortem examination. ${ }^{23}$ The disease involves a severe degeneration of the substantia nigra pars compacta as in Parkinson's disease and progressive supranuclear palsy (PSP). It differs, however, from Parkinson's disease, in which no appreciable degeneration of intrinsic striatal or pallidal neurons occurs, and from PSP, in which the striatum, internal pallidum, and brainstem nuclei are affected. ${ }^{4}$ Given these anatomopathological and clinically related differences, attempts are being made to diagnose SND in living patients and to distinguish it from other parkinsonian syndromes such as Parkinson's disease or PSP.

The neuropsychological pattern of SND has been described in three studies. An exten- sive battery of tests, performed in one patient, showed difficulties in serial arm movements, letter fluency, and Brown-Peterson distractor tasks, whereas overall cognitive and affective states were in the same range as those of healthy control subjects. ${ }^{5}$ Surprisingly, the performance was normal in numerous tests investigating frontal lobe function, such as the Wisconsin card sorting test, design fluency, self ordering, and trail making test. The authors concluded that "structural involvement of the putamen resulted in dysfunctions usually associated with the primary motor cortex and orbitofrontal cortex while sparing functions of other frontal regions as well as temporal and parietal cortices." Such an interpretation is not in line, however, with the results of another study performed in 16 patients with multiple system atrophy, most cases being of the SND type. ${ }^{6}$ The deficits of patients with multiple system atrophy in an attentional set shifting test, a subject ordered test of spatial working memory, and the Tower of London task were interpreted as a frontal lobe like dysfunction, similar to that in other degenerative diseases affecting the basal ganglia such as Parkinson's disease and PSP. ${ }^{7}$ In this study, however, no comparison was made with other groups of patients and the relative severity and specificity of the cognitive pattern of patients with SND was not assessed. A more recent study showed a similar pattern of cognitive dysfunction in 19 patients diagnosed as having multiple system atrophy of SND type and 19 with idiopathic Parkinson's disease. ${ }^{8}$

With tests of executive and memory functions sensitive to "subcortico-frontal dementia", 9 the neuropsychological profile of SND was compared with that of patients with Parkinson's disease and PSP, matched for age at the beginning of the disease, duration of evolution, severity of dementia, and depression.

\section{Patients and methods}

PATIENTS

Fourteen consecutive patients with probable SND agreed to participate in the study. Table 1 shows their principal characteristics. Probable SND was diagnosed from the following criteria: (a) disease duration less than 10 years; (b) parkinsonian syndrome poorly or unresponsive (motor improvement less than $25 \%$ ) to levodopa (mean daily dose $750 \mathrm{mg}$ ); (c) autonomic failure suggested by genitourinary symptoms with abnormal urological 
investigations associated or not with orthostatic hypotension and abnormal autonomic tests on electrocardiography; (d) absence of dementia, supranuclear ophthalmoplegia, apraxia, and focal lesions on CT or MRI. ${ }^{1}$

Fourteen patients with Parkinson's disease were matched with patients with SND for all parameters of the disease, except the mean basal score (motor score at the time of maximum disability without levodopa, evaluated with the motor subscale of the UPDRS scale), ${ }^{10}$ which was less severe in patients with Parkinson's disease, and the response to levodopa, which was less in patients with SND. The diagnosis of Parkinson's disease was based on the following criteria: (a) existence of either akinetorigid syndrome, or resting tremor, or both; $(b)$ good response (higher than $25 \%$ ) to levodopa treatment at the time of evaluation; (c) absence of clinical signs considered as characteristic of SND, PSP, or corticobasal degeneration, and of focal lesions on CT or MRI.

Fourteen patients with PSP were also matched with patients with SND for all parameters, except the Mattis dementia rating scale score, which was lower than in patients with SND (table 1). Patients with PSP met the following criteria ${ }^{11}:(a)$ progressive course of the disease; $(b)$ disease duration less than 10 years; $(c)$ extrapyramidal signs; $(d)$ poor response $(<25 \%)$ to levodopa treatment; $(e)$ vertical ophthalmoplegia sparing oculocephalic reflexes; $(f)$ falls; $(g)$ existence of either pseudobulbar palsy or dystonic dysarthria; and ( $h$ ) no evidence of focal lesions on clinical examination or CT.

The three groups of patients were matched for severity of depression evaluated with the Montgomery and Asberg depression rating scale. $^{12}$

\section{NEUROPSYCHOLOGICAL ASSESSMENT}

Besides the mini mental state examination ${ }^{13}$ and the Mattis dementia rating scale, ${ }^{14}$ intellectual and memory performance was evaluated by the verbal subtests of the revised Wechsler adult intelligence scale, the Raven 47 coloured progressive matrices, and the Wechsler memory scale.

Tests of executive function included the simplified version of the Wisconsin card sorting test, ${ }^{15}$ verbal fluency tests (names of animals in one minute and words beginning with $M$ in one minute), ${ }^{16}$ and graphic series. ${ }^{17}$ Behavioural abnormalities (prehension, imitation, utilisation behaviours; inertia, indifference) found in patients with frontal lobe lesions ${ }^{18}$ were also assessed, using a scale with precise steps going from 4 (normal behaviour) to 0 (very severe abnormality) for each behaviour. For instance, the score of imitation behaviour was 4 if the patient was only perplexed by the examiner's arbitrary gestures; 3 if the patient asked if he had to imitate; 2 if the patient imitated, but stopped when he was asked by the examiner to not imitate; 1 if the patient imitated again after a few seconds of distraction; 0 if the patient continued imitating while the examiner was saying to not imi- tate. From the global performance at these various tasks of executive functions and behaviours, a "frontal score", which has been shown to be related to frontal hypometabolism in PSP, ${ }^{19}$ was evaluated (maximal score: 60 points).${ }^{11}$ It included the number of criteria established in the Wisconsin card sorting test $(\times 3,+2$ points if the number of responses needed is $<43$, giving a maximum score of $20)$, the sum of the verbal fluency test scores (13. giving a maximum score of 10 points), graphic series (giving a maximum score of 10 points), and behaviours (giving a maximum score of 20 points). Additional tests of executive functions included the Stroop test ${ }^{20}$ and the trail making test. ${ }^{21}$

More specific verbal learning tests, which assess levels and mechanisms of performance, such as the California verbal learning test, ${ }^{22}$ and which control encoding, such as the Grober and Buschke's test, ${ }^{23}{ }^{24}$ were also used to describe more precisely the pattern of spared and impaired components of memory functioning. In the California verbal learning test, the retention of a 16 item shopping list is measured by free recall after $(a)$ each of five learning trials, and $(b)$ after one trial with an interfering list, both immediately and after a 20 minute delay. The fact that the items to be remembered belong to four different semantic categories allows quantitative assessment of learning strategies (for example, semantic $v$ serial strategies), sensitivity to interference, and comparisons of free recall, cued recall, and recognition performance. In the Grober and Buschke's test encoding is controlled by asking the subject to point to and to read aloud each of the 16 items to be remembered, presented four at a time, in response to its semantic category. All 16 items have to be retrieved at immediate cued recall before starting memory assessment, across three consecutive series of free recall and cued recall with selective reminding. Any item not retrieved at cued recall is provided by the examiner and repeated by the subject. Correct responses at either free or cued recall for a given series are added to obtain a total recall score. Free recall, cued recall, and yes-no recognition performance are also measured after a 15 minute delay.

\section{STATISTICAL ANALYSIS}

To establish a cognitive profile in SND, all test scores were standardised taking $\mathrm{m}=100$ as the mean performance of normal control subjects of the same age as the patients and $\mathrm{SD}=15$ as the $\mathrm{SD}$ of the normal population. Scores of the control population were established on published norms or laboratory normative data. The scores of patients with SND were compared with these norms by Student's $t$ test. The standardised scores of the three groups of SND, Parkinson's disease, and PSP were compared together by analysis of variance (ANOVA). The calculation of Student's $t$ test to further compare patients with SND with those with Parkinson's disease or PSP was contingent on a significant global comparison among the three groups. To allow 
Table 1 Characteristics of patients with striatonigral degeneration (SND), Parkinson's disease (PD), and progressive supranuclear palsy (PSP)

\begin{tabular}{lcrr}
\hline & $S N D$ & $P D$ & \multicolumn{1}{c}{$P S P$} \\
\hline No of patients & 14 & 14 & 14 \\
Age at onset (y) & $58 \cdot 1(2 \cdot 6)$ & $58 \cdot 9(2 \cdot 5)$ & $63 \cdot 3(1 \cdot 5)$ \\
Duration (y) & $4 \cdot 8(0 \cdot 5)$ & $4 \cdot 4(0 \cdot 8)$ & $4 \cdot 4(0 \cdot 8)$ \\
Basal score & $40 \cdot 4(4 \cdot 1)$ & $27 \cdot 1(3 \cdot 6)^{\star \star}$ & $33 \cdot 9(4 \cdot 1)$ \\
Response to levodopa & $12 \cdot 4(2 \cdot 2)$ & $54 \cdot 6(6 \cdot 1)^{\star \star}$ & $3 \cdot 6(2 \cdot 3)$ \\
Education (y) & $10 \cdot 5(0 \cdot 9)$ & $10 \cdot 9(0 \cdot 9)$ & $9 \cdot 1(0 \cdot 5)$ \\
MMSE & $28 \cdot 5(0 \cdot 5)$ & $28 \cdot 0(0 \cdot 6)$ & $27 \cdot 3(0 \cdot 6)$ \\
Mattis DRS & $132 \cdot 8(2 \cdot 9)$ & $131 \cdot 7(2 \cdot 9)$ & $116 \cdot 8(2 \cdot 7)^{\star \star}$ \\
WAIS-R VS & $98 \cdot 5(4 \cdot 5)$ & $104 \cdot 5(4 \cdot 5)$ & $88 \cdot 0(3 \cdot 0)$ \\
PM 47 & $110 \cdot 5(3 \cdot 0)$ & $106 \cdot 0(4 \cdot 5)$ & $104 \cdot 5(3 \cdot 0)$ \\
Wechsler MS & $104 \cdot 5(3 \cdot 0)$ & $101 \cdot 5(4 \cdot 5)$ & $94 \cdot 0(3 \cdot 0)$ \\
MADRS & $12 \cdot 7(1 \cdot 3)$ & $13 \cdot 4(1 \cdot 2)$ & $14 \cdot 2(1 \cdot 2)$ \\
\hline
\end{tabular}

MMSE = mini mental state examination (normal score $>24)$; Mattis DRS = Mattis dementia rating scale (normal score of elderly subjects: mean $=137 \cdot 3, \mathrm{SD}=6.9$ ); WAIS-RVS $=$

Wechsler revised adult intelligence verbal scale (normal score: mean $=100, \mathrm{SD}=15$ ); PM $47=$ Raven's 47 coloured progressive matrices (normal score: mean $=100, \mathrm{SD}=15$ ); Wechsler MS $=$ Wechsler memory scale (normal score: mean $=100, \mathrm{SD}=15$ ); MADRS $=$ Montgomery a Asberg depression rating scale (for mildly depressed patients: mean $=15 \cdot 7, \mathrm{SD}=7 \cdot 0$ ). The
basal score is the motor score of the UPDRS scale:" evaluated at the time of maximum disability without levodopa. Results are mean (SEM).

${ }_{\star \star}^{\text {without levodopa. R }}<0.01 v$ SND.

Table 2 Raw scores of patients with striatonigral degeneration (SND), Parkinson's disease (PD) and progressive supranuclear palsy (PSP) on tests of executive function and explicit memory

\begin{tabular}{lrrr}
\hline & \multicolumn{1}{c}{$S N D$} & \multicolumn{1}{c}{$P D$} & \multicolumn{1}{c}{$P S P$} \\
\hline WCST criteria & $5 \cdot 0(0 \cdot 4)$ & $3 \cdot 3(0 \cdot 7)$ & $1 \cdot 8(0 \cdot 3)$ \\
$\quad$ perseveration & $2 \cdot 3(0 \cdot 6)$ & $13 \cdot 9(4 \cdot 0)$ & $30 \cdot 9(3 \cdot 1)$ \\
\% perseveration & $29 \cdot 8(7 \cdot 9)$ & $48 \cdot 7(11 \cdot 2)$ & $86 \cdot 7(4 \cdot 5)$ \\
Category fluency & $16 \cdot 9(1 \cdot 7)$ & $18 \cdot 9(1 \cdot 9)$ & $12 \cdot 1(1 \cdot 0)$ \\
Phoneme fluency & $8 \cdot 5(1 \cdot 0)$ & $9 \cdot 5(1 \cdot 6)$ & $4 \cdot 1(0 \cdot 6)$ \\
Frontal score & $49 \cdot 7(2 \cdot 6)$ & $42 \cdot 3(4 \cdot 4)$ & $25 \cdot 2(2 \cdot 2)$ \\
California A1 & $6 \cdot 1(0 \cdot 7)$ & $4 \cdot 9(0 \cdot 8)$ & $4 \cdot 4(0 \cdot 4)$ \\
A total & $44 \cdot 7(2 \cdot 9)$ & $38 \cdot 4(4 \cdot 3)$ & $29 \cdot 3(3 \cdot 3)$ \\
B & $5 \cdot 6(0 \cdot 8)$ & $4 \cdot 4(0 \cdot 6)$ & $3 \cdot 1(0 \cdot 4)$ \\
SDFR & $7 \cdot 3(0 \cdot 9)$ & $7 \cdot 8(1 \cdot 0)$ & $4 \cdot 4(0 \cdot 9)$ \\
SDCR & $8 \cdot 1(0 \cdot 7)$ & $9 \cdot 3(0 \cdot 9)$ & $6 \cdot 6(0 \cdot 6)$ \\
LDFR & $7 \cdot 8(0 \cdot 8)$ & $7 \cdot 9(1 \cdot 0)$ & $6 \cdot 4(0 \cdot 7)$ \\
LDCR & $8 \cdot 6(0 \cdot 7)$ & $8 \cdot 8(0 \cdot 9)$ & $7 \cdot 7(0 \cdot 6)$ \\
Correct recognitions & $13 \cdot 6(0 \cdot 6)$ & $14 \cdot 4(0 \cdot 5)$ & $13 \cdot 9(0 \cdot 5)$ \\
False recognitions & $2 \cdot 0(0 \cdot 8)$ & $2 \cdot 6(0 \cdot 8)$ & $3 \cdot 6(0 \cdot 8)$ \\
Grober free recall & $24 \cdot 9(1 \cdot 9)$ & $19 \cdot 4(2 \cdot 0)$ & $14 \cdot 5(1 \cdot 5)$ \\
$\quad$ total recall & $45 \cdot 8(0 \cdot 8)$ & $45 \cdot 6(0 \cdot 5)$ & $45 \cdot 1(0 \cdot 8)$ \\
LDFR & $8 \cdot 9(0 \cdot 8)$ & $9 \cdot 2(1 \cdot 0)$ & $5 \cdot 1(0 \cdot 6)$ \\
LDTR & $15 \cdot 7(0 \cdot 1)$ & $15 \cdot 4(0 \cdot 3)$ & $15 \cdot 7(0 \cdot 2)$ \\
\hline
\end{tabular}

SDFR = short delay free recall $;$ SDCR $=$ short delay cued recall $;$ LDFR = long delay free recall; $\mathrm{LDCR}=$ long delay cued recall; $\mathrm{LDTR}=$ long delay total recall. Results are mean $(\mathrm{SEM})$.

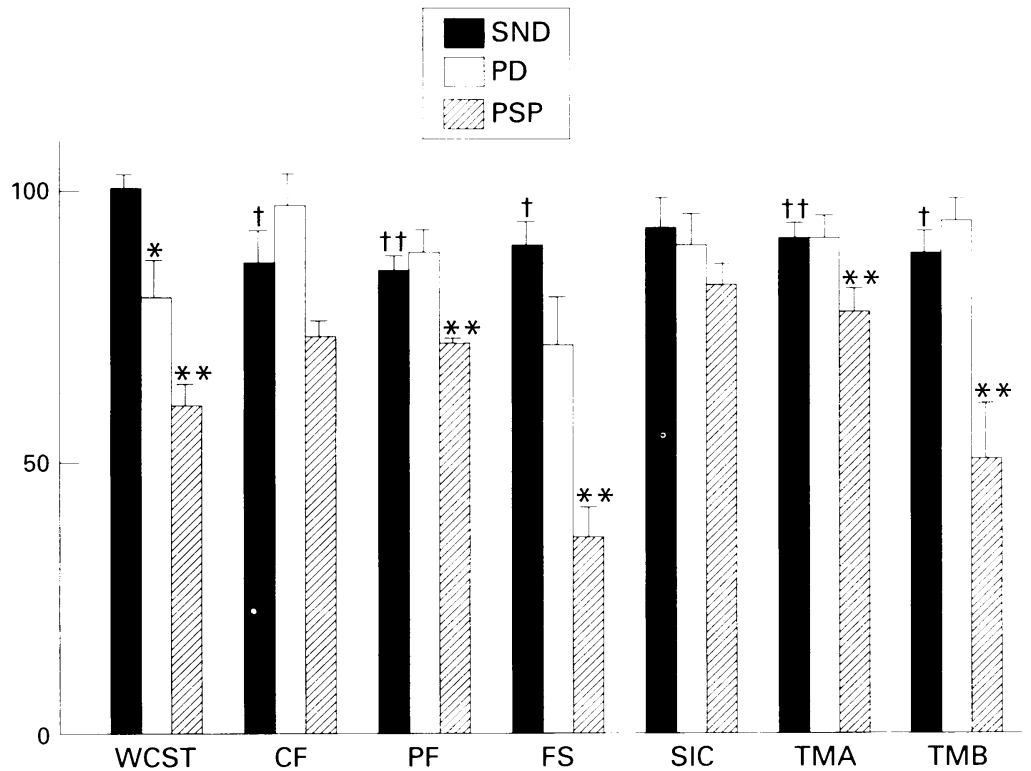

Figure 1 Tests of executive functions. Standardised scores $(m=100, S D=15)$ of patients with striatonigral degeneration (SND), Parkinson's disease (PD), and progressive supranuclear palsy (PSP) on the Wisconsin card sorting test (WCST; normal number of criteria for subjects of the same age: mean $=5, S D$ 1.4), category fluency $(C F$; normal score: mean $=22 \cdot 2, S D=5 \cdot 1)$, phonemic fluency $(P F$; normal score: mean $=$ $14 \cdot 3, S D=4 \cdot 5)$, global frontal score ( $F S$; normal score: mean $=56, S D=6)$, Stroop interference condition ( $S I C$; normal score: mean $=39, S D=10$ ), trail making test $A$ $(T M A$; normal score: mean $=48, S D=35)$ and $B(T M B$; mean $=119, S D=83)$. Results are expressed as mean (SEM). ${ }^{\star} p<0.05 ;{ }^{\star \star} p<0.01 \cup S N D ; \dagger p<0.05$; t†p $<0.01$ v controls. comparison with data provided in other studies, table 2 summarises the main raw scores of the three groups of patients.

\section{Results}

COMPARISON OF PATIENTS WITH SNI) ANI NORMAL CONTROL SUBIECTS

The overall performance of patients with SND on the verbal subtests of the revised Wechsler adult intelligence scale, the Raven 47 coloured progressive matrices, and the Wechsler memory scale was in the range of control subjects (table 1 ).

Tests of executive function showed a mildly impaired performance on the category ( $p<$ $0.02)$ and phonemic $(p<0.001)$ fluency, the global frontal score $(p<0.03)$, and the trail making test A $(\mathrm{p}<0.003)$ and $B(\mathrm{p}<0.03)$ (fig 1). Mild behavioural abnormalities were found in 11 patients: prehension behaviour in four, imitation behaviour in eight; but none displayed utilisation behaviour. Graphic series were impaired in five patients. On the other hand, the performance was normal on the interference condition of the Stroop procedure and on the Wisconsin card sorting test, not only for the number of criteria $(5 \cdot 0$ (SEM $0 \cdot 4)$ ), but also for the number of perseverative responses $(2 \cdot 3(0 \cdot 6))$.

The performance was normal in all the subtests of the California verbal learning test, except the short delay cued recall $(\mathrm{p}<0.03$; fig 2). In the procedure of Grober and Buschke, however, short and long delay free recall were impaired $(\mathrm{p}<0.01$; fig 3$)$.

COMPARISON OF PATIENTS WITH SND ANI) PATIENTS WITH PARKINSON'S disease

The Wisconsin card sorting test performance of patients with Parkinson's disease was significantly lower $(3.3(0.8)$ criteria, $\mathrm{p}<0.05$; 13.9 (3.9) perseverative responses, $\mathrm{p}<0.01$ ) than that in patients with SND (fig 1). There was no other significant difference between the two groups.

COMPARISON OF SND PATIENTS WITH PSP PATIENTS

Patients with PSP were significantly more impaired $(p<0.01)$ than patients with SND on most tests of executive function: the Wisconsin card sorting test $(1.8(0.3)$ criterion; $30.9(3.0)$ perseverative responses), phonemic fluency, the global frontal score and the Trail making test scores (fig 1). They also had a lower performance than patients with SND $(p<0.01)$ on the learning phase of the California verbal learning test (fig 2) and at free recall with the test of Grober and Buschke (fig 3).

\section{Discussion}

This study shows a normal overall cognitive and affective state in patients with SND (table 1) with only a mild impairment of memory and executive functions. Their performance was normal on the Wechsler memory scale and on nearly all the items of the California 


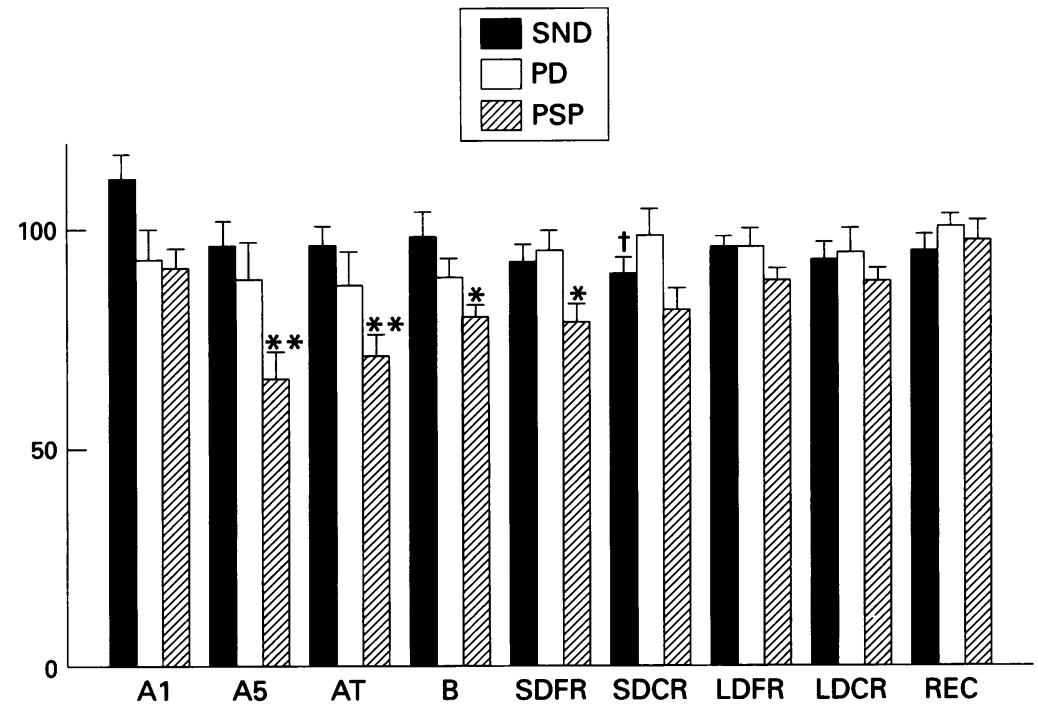

Figure 2 Califormia verbal learning test. Standardised scores $(m=100, S D=15)$ of patients with striatonigral degeneration (SND), Parkinson's disease (PD), and progressive supranuclear palsy (PSP). A1 = list $A$ first trial (normal score for subjects of the same age: mean $=5 \cdot 4, S D=1 \cdot 4) ; A 5=$ list $A$ fifth trial (normal score: mean $=11 \cdot 5, S D=2 \cdot 4$ ); $A T=$ list $A$ total (normal score: mean $=46 \cdot 2, S D=9 \cdot 1$ ); $B=$ interfering list $B$ (normal score: mean $=5 \cdot 9, S D=2 \cdot 1$ ); $S D F R=$ list $A$ short delay free recall (normal score: mean $=8 \cdot 8, S D=3 \cdot 0$ ); $S D C R=$ list $A$ short delay cued recall (normal score: mean $=10 \cdot 2$, $S D=2 \cdot 7) ; L D F R=$ list $A$ long delay free recall (normal score: mean $=9 \cdot 6, S D=2 \cdot 9$ ); $L D C R=$ list $A$ long delay cued recall (normal score: mean $=10 \cdot 6, S D=2 \cdot 4$ ); $R E C=$ recognition (normal score for recognition discriminability: mean $=98 \cdot 7, S D=4 \cdot 5$ ). Results are expressed as mean (SEM). ${ }^{\star} p<0.05 ;{ }^{\star \star} p<0.01 v$ SND; $\dagger p<0.05 v$ controls. gories may be sufficient in patients with SND to permit normal learning and free recall, but not to further improve performance at short delay cued recall. By contrast, with the procedure of Grober and Buschke, the individual encoding of each item may allow normal effects of semantic cueing of each item separately, but may not sustain normal free recall of the entire list. The dissociation between normal total recall and recognition and impaired free recall performance on the test of Grober and Buschke differs from the pattern of memory impairment found in the true amnesic syndrome of Alzheimer's disease, but is similar, although milder, to that found in demented patients with PSP, Parkinson's disease, and Huntington's disease. ${ }^{925}$ In these neurodegenerative diseases, characterised by the predominance of subcortical lesions, we have shown that deficit in the functional use of memory processes was highly correlated with the performance on tests of executive functions, whereas such correlations were not found in Alzheimer's disease. Because the memory pattern of performance of patients with SND did not differ in the present study from that in Parkinson's disease and PSP, we suggest that the mildly impaired memory performance in patients with SND likely results from an inefficient planning of memory processes. This interpretation is in agreement with the results of a previous study, in which the multiple system atrophy group showed "no significant deficits in tests of spatial and pattern recognition previously shown to be sensitive in patients early in the course of probable Alzheimer's disease" and impairments on other tests of visual memory and learning that "could not easily be related to fundamental deficits of memory and learning". ${ }^{6}$ Although the cognitive impairment of patients with SND was more global in another study, ${ }^{8}$ it was also interpreted as resulting from a frontal lobe like syndrome related to a dysfunction of the supervisory attentional system. ${ }^{26}$

Such a hypothesis is consistent with the deficits in tests and behaviours assessing frontal lobe functions, as the category and phonemic fluency, the pathological behaviours of prehension and imitation, and the trail making test (fig 1). Such a subcorticofrontal impairment has also been described in recent studies ${ }^{56}$ and may contribute to the mild cognitive deficit found in the Mattis dementia rating scale. The mild severity and the selectivity of the subcorticofrontal syndrome in SND must be underlined. It does not interfere with performance on tests such as the Wisconsin card sorting test and the Stroop interference condition, known to be particularly sensitive to frontal lobe dysfunction. $^{2728}$ It is far less severe than that of patients with PSP in nearly all tests of executive function. It is similar to that of patients with Parkinson's disease, but more selective, as the performance at the Wisconsin card sorting test was preserved in SND but impaired in Parkinson's disease. Previous studies showed no difference ${ }^{8}$ or only very 
subtle qualitative differences ${ }^{29}$ between the cognitive patterns of patients with multiple system atrophy and those with Parkinson's disease. The distinction, recently proposed, ${ }^{30}$ between spontaneous flexibility, requiring effective search strategies to move among categories of knowledge (as needed in verbal and design fluency tasks), and reactive flexibility, referring to the readiness to freely shift behaviour according to the particular context (as needed in the Wisconsin card sorting test), may account for the different patterns of dysexecutive syndromes in SND, PSP, and Parkinson's disease. According to this distinction, patients with SND would display impaired spontaneous flexibility (category and phonemic fluency, free recall in the procedure of Grober and Buschke), and a relatively preserved reactive flexibility (Wisconsin card sorting test, Stroop interference condition). By contrast, both forms of flexibility would be impaired in PSP, ${ }^{31}$ whereas the reactive flexibility would be particularly impaired in Parkinson's disease. ${ }^{32}$ The validity of such a distinction between two forms of cognitive flexibility has to be confirmed, however.

The cognitive abnormalities in PSP and Parkinson's disease are classically interpreted as resulting from the relatively stereotyped lesions found in the brain of patients. In PSP, the massive neuronal loss involves the basal ganglia and the upper brainstem, in particular the substantia nigra, striatum, pallidum, subthalamic nucleus, thalamus, and dentatus nucleus of the cerebellum, contrasting with the relative preservation of the prefrontal cortex. ${ }^{33}$ The severe frontal lobe like symtomatology characteristic of the disease $^{31}$ is considered to result essentially from the deafferentation of the prefrontal cortex from its subcortical projections via the thalamus. ${ }^{4}$ This interpretation has been corroborated by correlations between the severity of the dysexecutive syndrome and frontal hypometabolism in PET studies. ${ }^{19}$ By contrast, in non-demented patients with Parkinson's disease, most if not all lesions are confined to selective areas of the upper brainstem. The dysexecutive syndrome found in these patients is usually attributed to (a) the degeneration of the dopaminergic nigrostriatal pathway, resulting in the dysfunction of the striatofrontal circuits ${ }^{34} ;(b)$ the partial lesion of the ascending systems of neurotransmitters causing the demodulation of cortical areas implicated in cognitive functions. ${ }^{35}$

Because the dysexecutive syndrome in SND is far less dramatic than in PSP and as severe as in Parkinson's disease, the brain lesions in SND would be expected to be more limited than in PSP and of the same severity as in Parkinson's disease. The widespread lesions in the brain of patients with $\mathrm{SND}^{36-39}$ can be summarised as: (a) pronounced degeneration of the substantia nigra, more global than in Parkinson's disease, leading to a decline of striatal dopaminergic storage capacity, ${ }^{40}$ reflecting an equal loss of nigrocaudate and nigroputaminal dopaminergic fibres; $(b)$ severe loss of large and small neurons in the putamen and to a lesser degree in the caudate nucleus; (c) less conspicuous loss of neurons in the pallidum, cerebellum, corticospinal tract, and spinal cord; (d) partial degeneration of the noradrenergic and cholinergic systems; (e) relative preservation of thalamus, hypothalamic nuclei, and cerebral cortex (a laminar astrocytosis of layer 5 of the motor cortex has, however, been recently noted in multiple system atrophy). ${ }^{41}$ Two subcortical lesions could play a major part in the dysexecutive syndrome of SND: the massive degeneration of the dopaminergic nigrostriatal system, disturbing the neural circuits linking the striatum and the frontal cortex, ${ }^{34}$ and the damage of the striatum. That the dysfunction of the outputs from the basal ganglia towards the frontal cortex is very likely less severe than in PSP, may explain why the dysexecutive syndrome is milder in SND. As our and previous studies show similar cognitive impairment in SND and Parkinson's disease but more severe motor impairment in SND, it seems likely that at this stage of SND, the putamen, related to motor functions, is more involved, whereas the caudate nucleus, linked to cognitive functions, may still be relatively spared.

\section{Conclusion}

Patients with SND show a profile of cognitive deficits characterised by a selective impairment of executive functions. Given the relative preservation of the cerebral cortex in this disease, our results confirm the influence of the striatum and related striatofrontal circuits in cognitive functions. This frontal lobe like syndrome is similar to that found in Parkinson's disease, but milder than in PSP. Such a difference in severity of the dysexecutive syndrome may contribute to the clinical distinction between SND and PSP.

Drs F Calicis, $C$ Wyns, and $M$ Van der Linden allowed us to use their French adaptation of the procedure of Grober and Buschke. We thank Dr A Michon and Dr A M Bonnet for their help.

1 Quinn N. Multiple system atrophy-the nature of the beast. $\mathcal{f}$ Neurol Neurosurg Psychiatry 1989;52:S78-89.

2 Adams RD, Van Bogaert L, Van Der Eeken H. Dégénérescences nigrostriées et cérébello-nigro-striées. Psychiatria et Neurologia 1961;142:219-59.

3 Fearnley JM, Lees AJ. Striatonigral degeneration. A clinicopathological study. Brain 1990;113:1823-42.

4 Agid Y, Ruberg M, Dubois B, Pillon B. Anatomoclinical and biochemical concepts of subcortical dementia. In: Sthal SM, Iversen SD, Goodman EC, eds. Cognitive neurochemistry. Oxford: Oxford University Press, 1987: 248-71.

5 Sullivan EV, De La Paz R, Zipursky RB, Pfefferbaum A. Neuropsychological deficits accompanying striatonigral degeneration. fClin Exp Neuropsychol 1991;13:773-88.

6 Robbins TW, James M, Lange KW, Owen AM, Quinn NP, Marsden CD. Cognitive performance in multiple NP, Marsden CD. Cognitive performan
system atrophy. Brain 1992;115:271-91.

7 Pillon B, Dubois B, Ploska A, Agid Y. Severity and specificity of cognitive impairment in Alzheimer's, ficity of cognitive impairment in Alzheimer's, Huntington's, and Parkinson's diseases and progr
supranuclear palsy. Neurology 1991;41:634-43.

8 Testa D, Fetoni V, Soliveri P, Musicco M, Palazzini E, Girotti F. Cognitive and motor performance in multiple Girotti F. Cognitive and motor performance in multiple
system atrophy and Parkinson's disease compared.

9 Pillon B, Deweer B, Agid Y, Dubois B. Explicit memory in Alzheimer's, Huntington's and Parkinson's diseases. Arch Neurol 1993;50:374-79.

10 Fahn S, Elton RL, members of the UPDRS development committee. Unified Parkinson's disease rating scale. In: Fahn S, Marsden CD, Goldstein M, Calne DB, eds. Recent developments in Parkinson's disease. Vol 2. New York: MacMillan, 1987:153-63. 
11 Dubois B, Pillon B, Legault F, Agid Y, Lhermitte F. Slowing of cognitive processing in progressive supranu-
clear palsy: a comparison with Parkinson's disease. Arch Neurol 1988;45:1194-9.

12 Montgomery SA, Asberg M. A new depression scale designed to be sensitive to change. Br $\mathcal{F}$ Psychiatry 1979; 134:382-9.

13 Folstein MF, Folstein SE, McHugh PR. Mini-mental state: a practical method for grading the cognitive status state: a practical method for grading the cognitive status
of patients for the clinician. $\mathcal{F}$ Psychiatr Res 1975;12: of patients

14 Mattis R. Dementia rating scale. Odessa, FL: Psychological Assessment Resources, 1989.

15 Nelson HE. A modified card sorting test sensitive to frontal lobe defect. Cortex 1976;12:313-24.

16 Benton AL. Differential behavioural effects in frontal lobe disease. Neuropsychologia 1968;6:53-60.

17 Luria AR. Higher cortical functions in man. New York: Basic Books, 1966.

18 Lhermitte F, Pillon B, Serdaru M. Human autonomy and the frontal lobes. Part I: imitation and utilization behaviors: a neuropsychological study of 75 patients. Ann Neurol 1986;19:326-34.

19 Blin J, Baron JC, Dubois B, et al. PET study in progressive supranuclear palsy: brain hypometabolic pattern and supranuclear palsy: brain hypometabolic pattern and
clinicometabolic correlations. Arch Neurol 1990;47: 747-52.

20 Stroop JR. Studies of interference in serial verbal reactions. f Exp Psychol 1935;18:643-62.

21 Reitan RM. Validity of the trail making test as an indication of organic brain damage. Percept Mot Skills 1958; 8:271-6.

22 Delis DC, Kramer JH, Kaplan E, Ober BA. California verbal learning test: research edition. New York, NY: Psychological corporation, 1987.

23 Grober E, Buschke H. Genuine memory deficits in dementia. Developmental Neuropsychology 1987;3: 13-26.

24 Grober E, Buschke H, Crystal MD, Bang MA, Dresner R. Screening for dementia by memory testing. Neurology 1988;38:900-3.

25 Pillon B, Deweer B, Michon A, Malapani C, Agid Y, Dubois B. Are explicit memory disorders of progressive supranuclear palsy related to damage of striato-frontal supranuclear palsy related to damage
circuits? Neurology 1994;44:1264-70.

26 Shallice T. Specific impairment of planning. Philos Trans $R$ Soc Lond Biol 1982;298:211-26.

27 Milner B. Some effects of frontal lobectomy in man. In: Warren EM, Akert $\mathrm{K}$, eds. The frontal granular cortex and behavior. New York: McGraw-Hill, 1964:313-31.

28 Perret $\mathrm{E}$. The left frontal lobe of man and the suppression of habitual responses in verbal categorical behaviour. Neuropsychologia 1974;12:323-30.

29 Owen AM, Robbins TW. Comparative neuropsychology of parkinsonian syndromes. In: Wolters E, Scheltens P, eds. Mental dysfunction in Parkinson's disease. Proceedings of the European Congress on Mental Dysfunction in Parkinson's disease held in Amsterdam on 20-23 October 1993. Amsterdam: Vrije Universiteit, 1993:221-41.

30 Eslinger PJ, Grattan LM. Frontal lobe and fronto-striatal substrates for different forms of human cognitive flexisubstrates for different forms of human
bility. Neuropsychologia 1993;31:17-28.

31 Pillon B, Dubois B. Cognitive and behavioral impairments. In: Litvan I, Agid Y, eds. Progressive supranuclear palsy. Clinical and research approaches. Oxford: Oxford University Press, 1992:223-39.

32 Taylor AE, Saint-Cyr JA, Lang AE. Frontal lobe dysfunction in Parkinson's disease. Brain 1986;109:845-83.

33 Jellinger KA, Bancher C. Neuropathology. In: Litvan I Agid Y, eds. Progressive supranuclear palsy. Clinical and research approaches. Oxford: Oxford University Press, 1992:44-88.

34 Alexander GE, DeLong MR, Strick PL. Parallel organization of functionally segregated circuits linking basal ganglia and cortex. Annu Rev Neurosci 1986;9:357-81.

35 Dubois B, Boller F, Pillon B, Agid Y. Cognitive deficits in Parkinson's disease. In: Boller F, Grafman J, eds. Handbook of neuropsychology. Vol 5. Amsterdam: Elsevier, 1991:195-240.

36 Bannister R, Oppenheimer DR. Degenerative diseases of the nervous system associated with autonomic failure. Brain 1972;95:457-74.

37 Spokes EG, Bannister R, Oppenheimer DR. Multiple system atrophy with autonomic failure. $f$ Neurol Sci $1979 ;$ 43:59-82.

38 Oppenheimer DR. Neuropathology of progressive autonomic failure. In: Bannister R, ed. Autonomic failure. Oxford: Oxford University Press, 1983:267-83.

39 Adams RD, Salam-Adams M. Striatonigral degeneration. In: Vinken PJ, Bruyn GW, Klawans HL, eds. Handbook of clinical neurology. Vol 5 (49): Extrapyramidal disorders. clinical neurology. Vol 5 (49): Extrapyramidal disorders.
Amsterdam: Elsevier Science Publishers BV, 1986: Amsterdam-12.

40 Brooks DJ, Salmon EP, Mathias CJ, et al. The relationship between locomotor disability, autonomic dysfunction, and the integrity of the striatal dopaminergic system in patients with multiple system atrophy, pure autonomic failure, and Parkinson's disease, studied with PET Brain 1990;113:1539-52.

41 Fujita T, Doi M, Ogata T, Kanazava I, Misuzava $H$. Cerebral cortical pathology of sporadic olivopontocerebellar atrophy. F Neurol Sci 1993;116:41-6. 